\title{
Impact of epidermal growth factor receptor sensitizing mutations on outcomes of patients with non-small cell lung cancer treated with definitive thoracic radiation therapy: a systematic review and meta-analysis
}

\author{
Yu Yang Soon ${ }^{1,2,3}$, Balamurugan Vellayappan ${ }^{1,2,3}$, Jeremy Chee Seong Tey ${ }^{1,2,3}$, \\ Cheng Nang Leong ${ }^{1,2,3}$, Wee Yao Koh ${ }^{1,2,3}$ and Ivan Weng Keong Tham ${ }^{1,2,3}$ \\ ${ }^{1}$ Department of Radiation Oncology, National University Cancer Institute, Singapore \\ ${ }^{2}$ National University Hospital, Singapore \\ ${ }^{3}$ National University of Singapore, Singapore \\ Correspondence to: Yu Yang Soon, email: yysoon01@gmail.com
}

Keywords: non-small cell lung cancer, epidermal growth factor receptor, radiotherapy, chemo-radiotherapy, prognosis

Received: July 04, $2017 \quad$ Accepted: August 29, $2017 \quad$ Published: September 18, 2017

Copyright: Soon et al. This is an open-access article distributed under the terms of the Creative Commons Attribution License 3.0 (CC BY 3.0), which permits unrestricted use, distribution, and reproduction in any medium, provided the original author and source are credited.

\section{ABSTRACT}

Background: To determine if the presence of epidermal growth factor receptor (EGFR) sensitizing mutations improves tumor control and survival outcomes in patients with non-metastatic non-small cell lung cancer (NSCLC) who received definitive thoracic radiation therapy (TRT) with or without chemotherapy.

Materials and Methods: We searched MEDLINE for eligible comparative studies which compared the outcomes of patients treated with definitive TRT according to EGFR mutation status. Meta-analysis was performed using random effects model. Outcomes of interest were tumor overall response rate (ORR), loco-regional (LRR), distant recurrence rates (DRR), relapse-free survival (RFS), overall survival (OS) and adverse events (AE).

Results: We found seven studies including 537 patients with stage III NSCLC. Up to $45 \%$ of patients in the studies had mutations in exon 19 and 21 . Patients harbouring EGFR sensitizing mutations had a trend towards improvement in ORR (risk ratio $1.17,95 \%$ confidence interval $0.99-1.37, P=0.06$ ) compared to EGFR wild type status. There were no significant differences in LRR, DRR, RFS, OS and AE outcomes between the EGFR mutant and EGFR wild type groups.

Conclusions: The presence of EGFR sensitizing mutations may improve tumour response rate but not survival in patients with localized NSCLC treated with definitive thoracic radiation therapy with or without chemotherapy.

\section{INTRODUCTION}

Lung cancer accounted for 1.8 million new cases and 1.59 million deaths worldwide in 2012 [1]. Adenocarcinoma is the most prevalent histologic type [2]. Epidermal growth factor receptor (EGFR) is one of the mutated protooncogenes in lung adenocarcinoma, where a sensitizing EGFR mutation can result in constitutive activation of tyrosine kinase (TK) and phosphorylation of downstream pathways leading to uncontrolled proliferation, invasion and metastasis. The frequency of EGFR sensitizing mutations ranges from $15 \%$ of lung adenocarcinoma in Caucasian populations to as high as 50\% in Asian populations [3-4].
A meta-analysis of 13 randomized trials have shown that EGFR TK inhibitors (TKIs) such as gefitinib or erlotinib delay disease progression significantly but do not improve overall survival compared to first line platinum based chemotherapy in Stage IV lung adenocarcinoma harbouring EGFR sensitizing mutations [5]. The lack of overall survival benefit with EGFR TKIs in these randomized trials is most likely due to the use of these EGFR TKIs as second line therapy after progression on first line chemotherapy $[6,7]$. These trials established EGFR TKIs as first line systemic therapy for patients with Stage IV lung adenocarcinoma harbouring EGFR sensitizing mutations [8]. 
Currently, there is no defined role of EGFR TKIs for patients with Stage I to III lung adenocarcinoma. Definitive thoracic radiation therapy (TRT) with or without chemotherapy remains one of the recommended curative treatment options [8]. Although in-vitro studies suggest that non-small cell lung cancer (NSCLC) cell lines with EGFR mutations have increased sensitivity to radiation compared to EGFR wild-type cell lines [9], it is unclear if patients harbouring these mutations have improved clinical outcomes when treated with definitive TRT compared with patients with EGFR wildtype status. Hence, we performed a systematic review and meta-analysis of comparative studies to determine the impact of EGFR sensitizing mutations on tumour overall response rates, locoregional and distant disease recurrence rates, recurrence-free and overall survival as well as toxicity outcomes in patients with non-metastatic lung adenocarcinoma treated with definitive TRT with or without chemotherapy. The knowledge gained from our findings may help with patient prognostication.

\section{RESULTS}

\section{Results of search strategy}

We identified seven comparative studies including 537 patients using the search strategy summarized in Figure 1 [10-16]. We screened through 90 records and retrieved 42 full text articles for further assessment. Thirty four articles were excluded as they did not compare the outcomes of the study participants according to their EGFR mutation status. One study was excluded as the participants received adjuvant TRT.

\section{Characteristics of included studies}

The characteristics of the seven included studies are summarized in Table 1. Five of the included studies were single institutional retrospective cohort studies [11-13, 15-16] while the other two were retrospective analysis of prospective single arm clinical trials $[10,14]$. The median sample size was 44 (range 34 to 184). Six studies included only patients with stage III disease treated with TRT [10-11, 13-16]. All studies tested for the presence of exon 19 deletion or L858R missense mutation in exon 21. For each study, 10 to $45 \%$ of patients had EGFR sensitizing mutations. The reported total thoracic radiation dose among the included studies ranged from 40 to 74 Gy. Only two studies required all patients to receive concurrent platinum doublet chemotherapy [14-15]. There were only two studies that mandated all patients harbouring EGFR sensitizing mutations to receive EGFR TKIs $[10,14]$.

Formal critical appraisal of the seven studies showed that the risk of bias was low to moderate in four studies (quality score B1) [10, 14-16], moderate to high in two studies (quality score B2) $[10,13]$ and high in one study (quality score C) [12].

\section{Tumour overall response rates}

Five studies reported the rates of the partial and complete tumour response. Four studies defined tumour response as per RECIST 1.1 [11-12, 15-16], while one study used RECIST 1.0 [13]. There was no significant differences in tumour overall response rates (partial + complete response) between EGFR sensitizing mutations and wild type groups (RR 1.17, 95\% confidence interval (CI) 0.99 to $1.37, P=0.06$; Figure 2 ). There was no statistically significant heterogeneity in the RR for overall response rate (chi square $P=0.16, \mathrm{I}^{2}=40 \%$ ). There were no significant differences in effects on overall response rates between subgroups defined by study design, use of concurrent chemotherapy or EGFR TK inhibitors (Table 2). The quality of evidence judged by the GRADE approach was deemed to be very low.

\section{Loco-regional disease recurrence rates}

Five studies reported the rates of loco-regional disease recurrence [12-16]. Only one study defined locoregional disease recurrence as recurrence of disease within the RT fields [16]. The other four studies did not define loco-regional disease recurrence although the results were reported [12-15]. There was no significant differences in loco-regional disease recurrence between EGFR sensitizing mutations and wild type groups (RR 0.65, 95\% CI 0.28 to $1.52, P=0.32$; Figure 3 ). There was significant heterogeneity among the trial results (chi square $P=0.05$, $\mathrm{I}^{2}=58 \%$ ). There were no significant differences in effects on locoregional disease recurrence between subgroups defined by study design, use of concurrent chemotherapy or EGFR TK inhibitors (Table 3). The quality of evidence judged by the GRADE approach was deemed to be very low.

\section{Distant disease recurrence rates}

Five studies reported rates of distant disease recurrence [12-16]. Only one study defined distant disease recurrence as recurrence of disease outside the RT fields [16]. The other four studies did not define distant disease recurrence although the results were reported [12-15]. There was no significant differences in distant disease recurrence between EGFR sensitizing mutations and wild type groups (RR 1.46, 95\% CI 0.97 to 2.18, $P=0.07$; Figure 4). There was significant heterogeneity among the trial results (chi square $P=0.004, \mathrm{I}^{2}=74 \%$ ). The effect on disease recurrence rates were greater in study that conduct retrospective analysis of a prospective clinical trial than retrospective single institutional studies (RR 2.74 versus (vs) 1.28, interaction $P=0.03$ ); greater in studies that mandate the use of concurrent chemotherapy than studies which did not (RR 2.15 vs 1.05 , interaction $P=0.03$ ); greater in study that mandates the use of EGFR TK inhibitors than studies which did not (RR 2.74 versus (vs) 1.28 , interaction $P=0.03$ ) (Table 4 ). The quality of 
Table 1: Characteristics of included studies

\begin{tabular}{|c|c|c|c|c|c|c|c|c|c|c|c|c|}
\hline Study & $\begin{array}{c}\text { Year } \\
\text { published }\end{array}$ & Study design & $\begin{array}{l}\text { Sample } \\
\text { size }\end{array}$ & $\begin{array}{l}\text { Median } \\
\text { age }\end{array}$ & $\begin{array}{l}\text { Stage } \\
\text { III (\%) }\end{array}$ & $\begin{array}{c}\text { EGFR mutations } \\
\text { tested }\end{array}$ & $\begin{array}{c}\text { EGFR } \\
\text { activating } \\
\text { mutation } \\
(\%)\end{array}$ & $\begin{array}{l}\text { Total Thoracic } \\
\text { RT dose } \\
\text { received } \\
\text { (EQD2) }(\mathrm{Gy})\end{array}$ & $\begin{array}{l}\text { Received } \\
\text { concurrent } \\
\text { chemo }(\%)\end{array}$ & $\begin{array}{l}\text { Systemic therapy } \\
\text { regimens }\end{array}$ & $\begin{array}{c}\text { EGFR } \\
\text { mutant } \\
\text { receiving } \\
\text { EGFR TKI } \\
(\%)\end{array}$ & $\begin{array}{l}\text { Global } \\
\text { score }\end{array}$ \\
\hline Ready & 2010 & \begin{tabular}{l|} 
Retrospective \\
analysis of \\
prospective \\
single arm trial
\end{tabular} & 43 & NR & 100 & $\begin{array}{l}\text { Exon } 19 \text { deletions } \\
\text { and mutations in } \\
\text { exon } 18,20 \text { and } 21\end{array}$ & 26 & 66 & Not reported & $\begin{array}{l}\text { Induction phase: } 2 \text { cycles } \\
\text { of Paclitaxel } 200 \mathrm{mg} / \mathrm{m} 2 \\
\text { plus Carboplatin area } \\
\text { under curve } 6 \text { every } 21 \\
\text { days plus Gefitinib } 250 \mathrm{mg} \\
\text { daily } \\
\text { Concurrent phase: } \\
\text { Gefitinib } 250 \mathrm{mg} \text { daily or } \\
\text { weekly Paclitaxel } 50 \mathrm{mg} / \\
\text { m2 with Carboplatin area } \\
\text { under curve } 2 \text { for } 7 \text { weeks } \\
\text { Maintenance phase: } \\
\text { Gefitinib } 250 \mathrm{mg} \text { daily till } \\
\text { disease progression or } \\
\text { unacceptable side effects }\end{array}$ & 100 & B1 \\
\hline $\mathrm{Li}$ & 2011 & $\begin{array}{l}\text { Retrospective } \\
\text { cohort study }\end{array}$ & 87 & NR & 100 & $\begin{array}{l}\text { Exon } 19 \text { deletions } \\
\text { and mutations in } \\
\text { exon } 21\end{array}$ & 45 & $40-70$ & 59 & Not reported & 41 & B2 \\
\hline Hayashi & 2012 & $\begin{array}{l}\text { Retrospective } \\
\text { cohort study }\end{array}$ & 34 & 69 & 97 & $\begin{array}{l}\text { Exon } 19 \text { deletions } \\
\text { and mutations in } \\
\text { exon } 18 \text { and } 21\end{array}$ & 32 & Not reported & 88 & Not reported & Not reported & $\mathrm{C}$ \\
\hline Akamatsu & 2014 & $\begin{array}{l}\text { Retrospective } \\
\text { cohort study }\end{array}$ & 44 & 66 & 100 & $\begin{array}{l}\text { Exon } 19 \text { deletions } \\
\text { and mutations in } \\
\text { exon } 18,20 \text { and } 21\end{array}$ & 30 & $56-74$ & 91 & \begin{tabular}{|l|} 
Cisplatin plus S-1 or \\
Cisplatin plus Vinorelbine \\
or Carboplatin plus \\
Paclitaxel
\end{tabular} & 77 & B2 \\
\hline Komaki & 2015 & \begin{tabular}{l|} 
Retrospective \\
analysis of \\
prospective \\
single arm trial
\end{tabular} & 41 & NR & 100 & $\begin{array}{l}\text { Exon } 19 \text { deletions } \\
\text { and mutations in } \\
\text { exon } 18,20 \text { and } 21\end{array}$ & 10 & 60 & 100 & $\begin{array}{l}\text { Concurrent phase: weekly } \\
\text { Paclitaxel } 45 \mathrm{mg} / \mathrm{m} 2 \text { plus } \\
\text { Carboplatin area under } \\
\text { curve } 2 \text { for } 7 \text { weeks plus } \\
\text { Erlotinib } 150 \mathrm{mg} \text { daily } \\
\text { from Tuesday to Sunday. } \\
\text { Consolidation phase: } 2 \\
\text { cycles of Paclitaxel } 200 \mathrm{mg} \\
\text { /m2 plus Carboplatin area } \\
\text { under the curve } 6 \text { every } \\
21 \text { days }\end{array}$ & 100 & B1 \\
\hline Tanaka & 2015 & $\begin{array}{l}\text { Retrospective } \\
\text { cohort study }\end{array}$ & 104 & 62 & 100 & $\begin{array}{l}\text { Exon } 19 \text { deletions } \\
\text { and mutations in } \\
\text { exon } 18,20 \text { and } 21\end{array}$ & 28 & $54-74$ & 100 & \begin{tabular}{|l|} 
Carboplatin plus \\
Paclitaxel or Cisplatin \\
plus Vinorelbine or \\
Cisplatin plus Docetaxel \\
or Cisplatin plus S-1 or \\
Cisplatin plus Pemetrexed \\
or Cisplatin plus \\
Irinotecan or Carboplatin \\
plus Vinorelbine
\end{tabular} & 72 & B1 \\
\hline Yagaishita & 2015 & $\begin{array}{l}\text { Retrospective } \\
\text { cohort study }\end{array}$ & 184 & 61 & 100 & $\begin{array}{l}\text { Exon } 19 \text { deletions } \\
\text { and mutations in } \\
\text { exon } 21\end{array}$ & 16 & 60 & 90 & $\begin{array}{l}\text { Cisplatin plus Vinorelbine } \\
\text { or Carboplatin plus } \\
\text { Paclitaxel }\end{array}$ & 69 & B1 \\
\hline
\end{tabular}

Global score: B1, low-moderate risk of bias; B2, moderate-high risk of bias; $\mathrm{C}$, high risk of bias.

evidence judged by the GRADE approach was deemed to be very low.

\section{Recurrence free survival}

Six studies reported recurrence free survival [10, $12-16]$. Four studies defined recurrence free survival as time from $1^{\text {st }}$ day of treatment (either radiation therapy, chemotherapy or both) to disease recurrence or death $[12-13,15-16]$. One study defined recurrence free survival as time from enrolment to disease recurrence or death [10]. One study did not define recurrence free survival although the results were reported [14]. There was no significant differences in disease recurrence free survival between EGFR sensitizing mutations and wild type groups (HR 1.33, 95\% CI 0.90 to $1.97 ; P=0.15$; Figure 5). There was significant heterogeneity among the trial results (chi square $P=0.07, \mathrm{I}^{2}=51 \%$ ). The effect on recurrence free survival was greater in studies that mandate the use of concurrent chemotherapy than studies than did not (HR 2.47 vs 1.01, interaction $P=$ 0.002 ). There were no significant differences in effects on recurrence free survival between subgroups defined by study design and use of EGFR TKIs (Table 5). The quality of evidence judged by the GRADE approach was deemed to be very low.

\section{Overall survival}

All studies reported overall survival [10-16]. Two studies defined overall survival as time from enrolment to death $[10,14]$. Two studies defined overall survival as time from diagnosis to death [11-12]. Three studies defined overall survival as time from $1^{\text {st }}$ day of treatment (either radiation therapy, chemotherapy or both) to death $[13,15-16]$. There was no significant difference 
in overall survival between EGFR sensitizing mutation and wild-type (HR $0.99,95 \%$ CI 0.75 to $1.29 ; P=0.92$; Figure 6). There was no significant heterogeneity among the trial results (chi square $P=0.80, \mathrm{I}^{2}=0 \%$ ). There were no significant differences in effects on overall survival between subgroups defined by study design, use of concurrent chemotherapy or EGFR TKIs (Table 6). The quality of evidence judged by the GRADE approach was deemed to be very low.

\section{Adverse events}

Only one study compared the adverse events outcomes between EGFR sensitizing mutations and wildtype [14]. There was no significant difference in incidence and severity of esophagitis, pneumonitis, skin toxicity and fatigue between the EGFR mutant and wild type groups.

\section{DISCUSSION}

This meta-analysis showed that there was no difference in overall tumour response rate, recurrence free or overall survival between EGFR sensitizing mutations and wild type groups. However, these findings were based on very low quality evidence.
Our results were consistent with published metaanalyses that demonstrated that EGFR sensitizing mutations were not prognostic for localized NSCLC treated with definitive chemoradiotherapy or surgery [17-19]. Ochiai and colleagues performed a systematic review and meta-analysis of three retrospective nonrandomized comparative studies to determine the impact of EGFR sensitizing mutations in locally advanced NSCLC treated with concurrent chemo-radiotherapy on patterns of recurrence, recurrence-free and overall survival [17]. They found that there was no difference in disease recurrence, recurrence free and overall survival between EGFR mutated and EGFR wild-type NSCLC, but there was a higher incidence of distant disease recurrence rate and lower incidence of locoregional recurrence rate for EGFR mutated NSCLC. We acknowledged that while the results of our review were mostly consistent with findings of the review reported by Ochiai et al., there are some key differences between the two reviews. Firstly, our population of interest is much broader as we included patients treated with definitive thoracic radiation therapy with or without chemotherapy. Secondly, we included a thorough review on the methodological quality of the included studies as well as an appraisal of the summarized evidence which Ochiai et al. did not perform. Thirdly, we

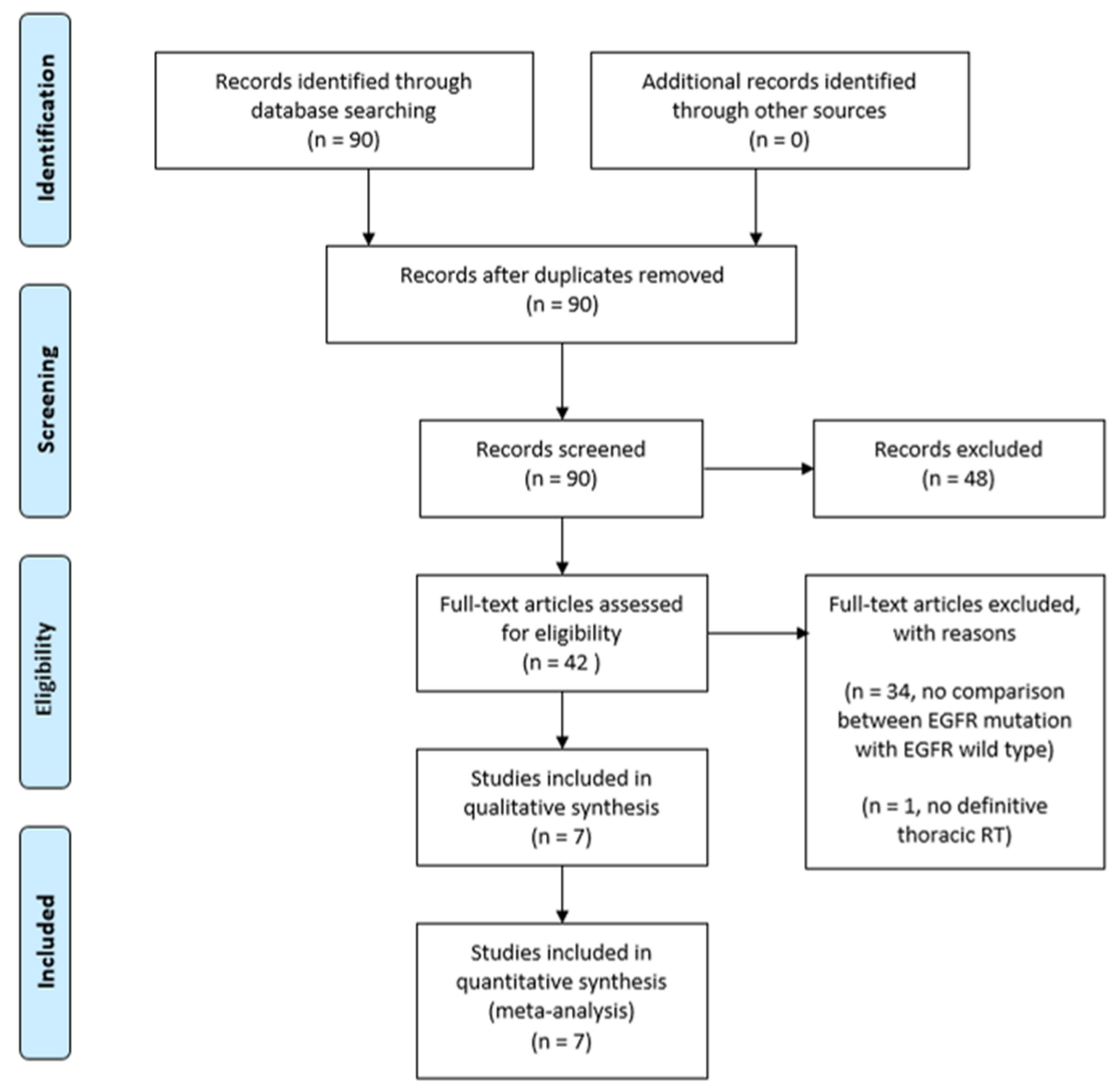

Figure 1: Results of search strategy. 
Table 2: Subgroup effects on overall response rates

\begin{tabular}{|c|c|c|c|c|}
\hline Subgroup & Patients & Risk Ratio & $95 \% \mathrm{CI}$ & Interaction $P$ \\
\hline \multicolumn{5}{|l|}{ Study Design } \\
\hline Retrospective analysis of prospective single arm clinical trial & 41 & 1.09 & 0.78 to 1.50 & \multirow[t]{2}{*}{0.63} \\
\hline Retrospective single institution cohort study & 409 & 1.19 & 0.98 to 1.45 & \\
\hline \multicolumn{5}{|l|}{ Use of concurrent chemotherapy } \\
\hline Mandatory & 145 & 1.04 & 0.84 to 1.27 & \multirow[t]{2}{*}{0.22} \\
\hline Not Mandatory & 205 & 1.27 & 0.99 to 1.63 & \\
\hline \multicolumn{5}{|l|}{ Use of EGFR TK inhibitors } \\
\hline Mandatory & 41 & 1.09 & 0.78 to 1.50 & \multirow[t]{2}{*}{0.63} \\
\hline Not mandatory & 409 & 1.19 & 0.98 to 1.45 & \\
\hline
\end{tabular}

used a random effects model to meta-analysed the results of the included studies, whereas Ochiai et al. adopted a fixed effects model. We believe that it is more appropriate to use a random effects model as there were variation in patient characteristics, utilization rate of concurrent chemotherapy or EGFR TKIs and definition of endpoints among the included studies.

Zhang et al. performed a publication based metaanalysis of 16 studies examining the impact of EGFR sensitizing mutations on disease-free and survival outcomes in resected NSCLC [18]. They found that the presence of EGFR sensitizing mutations was not a prognostic factor in patients with resected NSCLC, but the methodologic quality of the included studies was modest. The findings reported by Zhang et al. were recently confirmed by Shepherd and colleagues who evaluated the prognostic and predictive roles of TP53/KRAS and TP53/EGFR co-mutations in 3,533 patients from the LACE (Lung Adjuvant Cisplatin Evaluation) database of randomized trials of adjuvant chemotherapy versus observation in early stage resected NSCLC [19]. They found that EGFR or KRAS and TP53 tumour suppressor co-mutations had no prognostic effect in resected NSCLC.

Guidelines from the College of American Pathologists, International Association for the Study of Lung Cancer, Association for Molecular Pathology and American Society of Clinical Oncology stated that $[20,21]$

1. EGFR mutation testing should be performed at the time of diagnosis for patients with stage IV disease who are suitable for therapy or at a time of recurrence or progression in patients who originally presented with lower-stage disease but were not previously tested.

2. EGFR mutation testing of tumours at diagnosis from patients presenting with stage I to III disease is encouraged but the decision to do so should be made locally by each laboratory in collaboration with its oncology team.



Figure 2: Tumor overall response rates. 
Table 3: Subgroup effects on loco-regional disease recurrence rates

\begin{tabular}{|c|c|c|c|c|}
\hline Subgroup & Patients & Risk Ratio & $95 \% \mathrm{CI}$ & Interaction $P$ \\
\hline \multicolumn{5}{|l|}{ Study Design } \\
\hline Retrospective analysis of prospective single arm clinical trial & 41 & 0.21 & 0.01 to 2.91 & \multirow{2}{*}{0.38} \\
\hline Retrospective single institution cohort study & 366 & 0.72 & 0.29 to 1.80 & \\
\hline \multicolumn{5}{|l|}{ Use of concurrent chemotherapy } \\
\hline Mandatory & 145 & 0.37 & 0.15 to 0.91 & \multirow{2}{*}{0.25} \\
\hline Not Mandatory & 262 & 0.91 & 0.26 to 3.10 & \\
\hline \multicolumn{5}{|l|}{ Use of EGFR TK inhibitors } \\
\hline Mandatory & 41 & 0.21 & 0.01 to 2.91 & \multirow{2}{*}{0.38} \\
\hline Not mandatory & 366 & 0.72 & 0.29 to 1.80 & \\
\hline
\end{tabular}

The benefits of upfront EGFR mutation testing in non-metastatic NSCLC include starting treatment early in patients who experience a recurrence as the molecular information is already available. Secondly biopsy taken when patients recurred or progressed may be of borderline quantity and quality and this may affect the results of EGFR testing. Hence testing on initial specimen may be preferable. The downsides of upfront EGFR mutation testing in non-metastatic NSCLC include the additional cost of performing these tests when the results may not be used to guide management in patients who never relapse after curative intent therapies. Secondly, the role of EGFR TKIs in non-metastatic NSCLC has not been established [8]. We are awaiting results of on-going trials such as RTOG 1306 to help determine whether adding upfront EGFR TKIs to standard concurrent chemo-radiotherapy would benefit patients with unresectable locally advanced EGFR mutated NSCLC [22].

We feel that the strengths of this review are as follows:

a. It addresses an important clinical question;

b. We evaluated the methodologic quality of the included studies as well as the quality of the summarized evidence using published tools

c. There was homogeneity among the trial results for overall survival outcomes.

However, the review was limited by:

a. Small number of included studies, all of which were not randomized

b.Quality of the summarized evidence being very low

c. Information gathered from published data rather than individual patient data.

In summary, we conclude that EGFR sensitizing mutations is not a significant prognostic marker for patients with non-metastatic NSCLC undergoing definitive thoracic radiotherapy, with or without chemotherapy.

\section{MATERIALS AND METHODS}

\section{Study criteria}

This meta-analysis incorporated studies comparing the outcomes of interests of patients, with newly

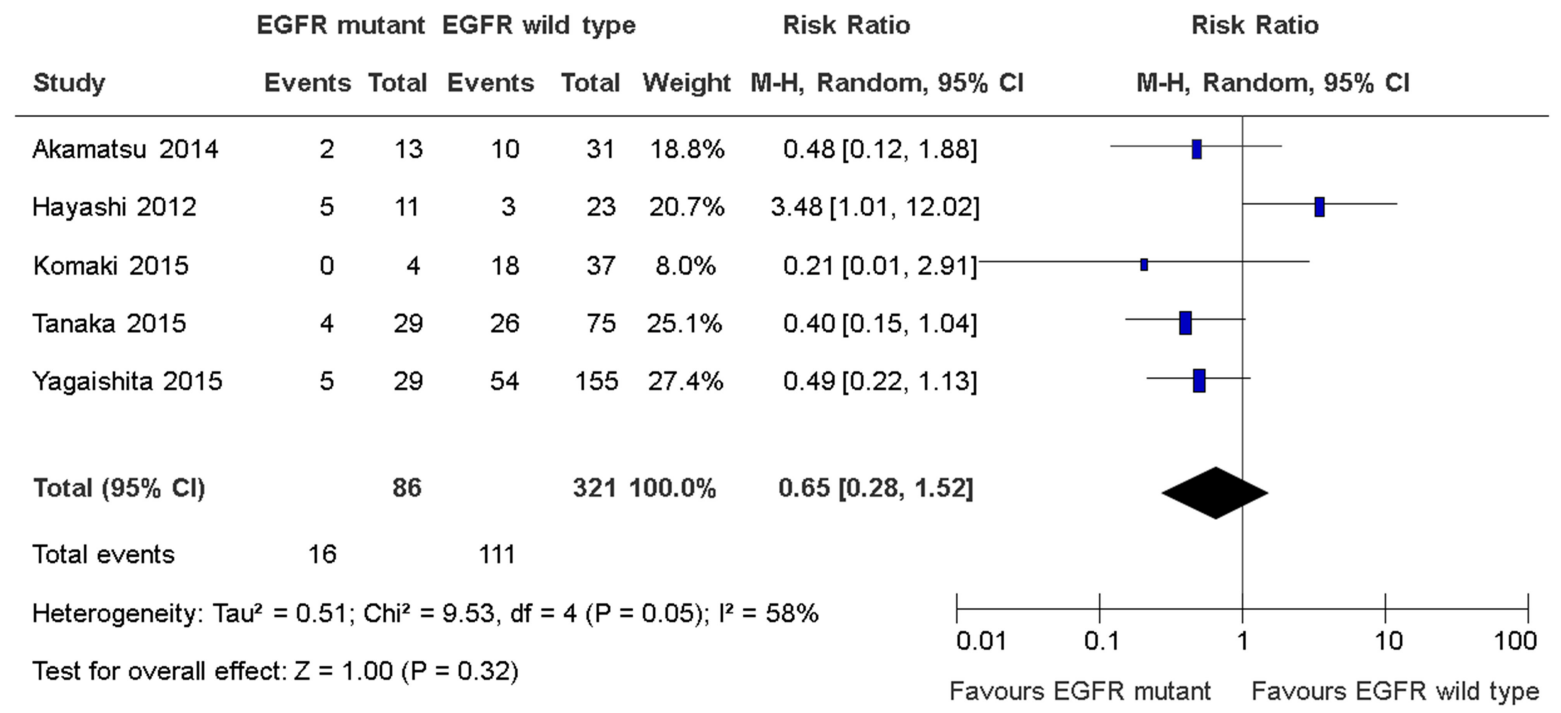

Figure 3: Loco-regional disease recurrence rates. 
Table 4: Subgroup effects on distant disease recurrence rates

\begin{tabular}{|c|c|c|c|c|}
\hline Subgroup & Patients & Risk Ratio & $95 \% \mathrm{CI}$ & Interaction $P$ \\
\hline \multicolumn{5}{|l|}{ Study Design } \\
\hline Retrospective analysis of prospective single arm clinical trial & 41 & 2.74 & 1.59 to 4.69 & \multirow[t]{2}{*}{0.03} \\
\hline Retrospective single institution cohort study & 366 & 1.28 & 0.85 to 1.92 & \\
\hline \multicolumn{5}{|l|}{ Use of concurrent chemotherapy } \\
\hline Mandatory & 145 & 2.15 & 1.51 to 3.06 & \multirow[t]{2}{*}{0.03} \\
\hline Not Mandatory & 262 & 1.05 & 0.61 to 3.06 & \\
\hline \multicolumn{5}{|l|}{ Use of EGFR TK inhibitors } \\
\hline Mandatory & 41 & 2.74 & 1.59 to 4.69 & \multirow[t]{2}{*}{0.03} \\
\hline Not mandatory & 366 & 1.28 & 0.85 to 1.92 & \\
\hline
\end{tabular}

diagnosed non-metastatic NSCLC treated with first-line definitive TRT with or without chemotherapy, who were classified according to their EGFR mutation status i.e. EGFR sensitizing mutations versus wild-type status. The EGFR mutations of interest included exon 19 deletions and L858R point mutations in exon 21. We included studies, either in English or Chinese language, where full publication was available.

\section{Search strategy}

Studies were identified by searching MEDLINE from the date of inception onwards to December 2016. The search strategy included the medical subject headings of "radiotherapy", "lung neoplasms" and "receptor, epidermal growth factor". The results were then hand searched for eligible trials.

\section{Selection of studies and data collection}

Three reviewers independently assessed the eligibility of abstracts identified by the search. The full text article of any study that appeared to meet the inclusion criteria were retrieved for closer examination. Disagreements were resolved by consensus.

The same three reviewers extracted the data independently using standardized data collection forms. The data retrieved from the reports include publication details, methodological components, study characteristics such as sample size, interventions, duration of follow up and outcome measures. The data extracted from the studies were entered into the Cochrane Collaboration software (RevMan version 4.2.9; http://www.cochrane.org).

\section{Methodologic quality assessment}

Quality assessment of each study was based on the reporting of the study methods and results namely: adequacy in the definition of the study participants with respect to time, place and person, percentage of participants refusing to participate, accuracy in measurement of outcomes, blinding in the measurement of risk factors and outcomes, whether all important risk factors were included in the analysis and percentage

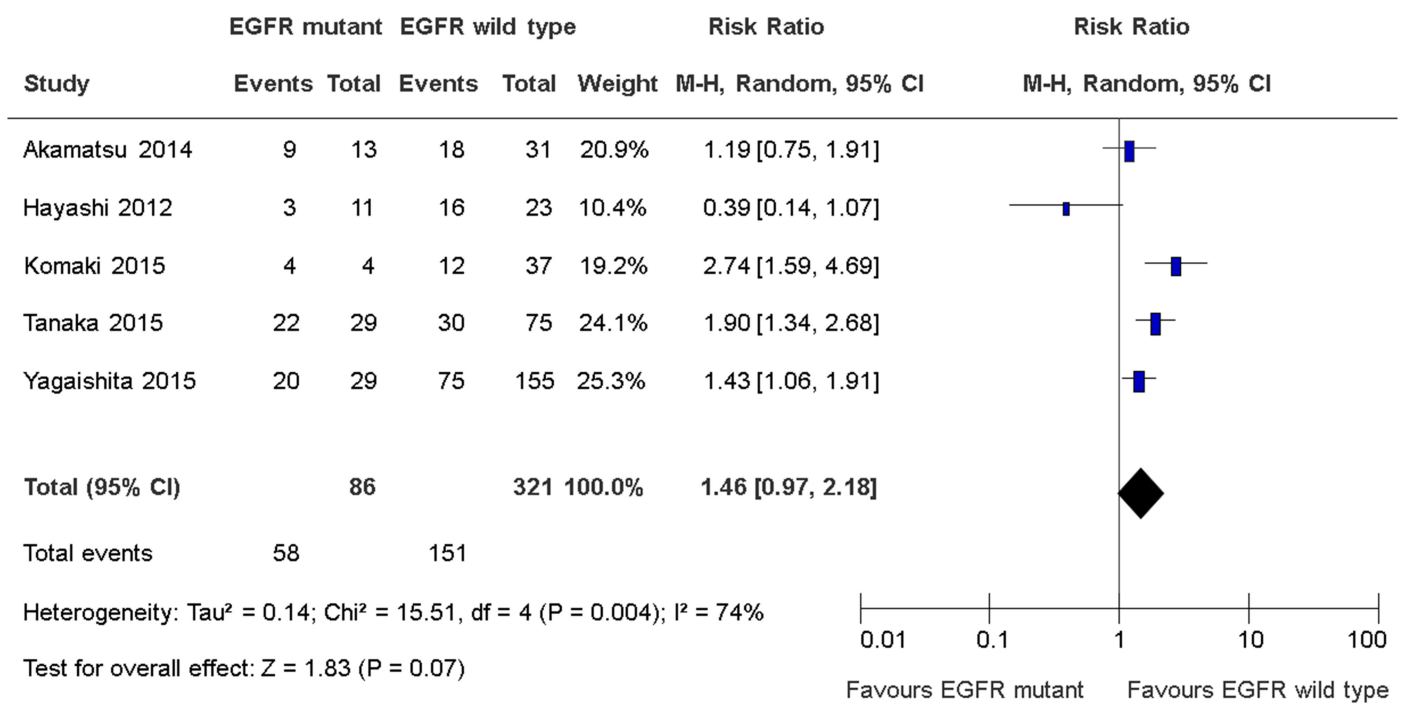

Figure 4: Distant disease recurrence rates. 
Table 5: Subgroup effects on recurrence free survival

\begin{tabular}{|c|c|c|c|c|}
\hline Subgroup & Patients & Hazard Ratio & $95 \% \mathrm{CI}$ & Interaction $P$ \\
\hline \multicolumn{5}{|l|}{ Study Design } \\
\hline Retrospective analysis of prospective single arm clinical trial & 84 & 1.43 & 0.65 to 3.16 & \multirow[t]{2}{*}{0.83} \\
\hline Retrospective single institution cohort study & 366 & 1.29 & 0.76 to 2.17 & \\
\hline \multicolumn{5}{|l|}{ Use of concurrent chemotherapy } \\
\hline Mandatory & 145 & 2.47 & 1.52 to 4.02 & \multirow[t]{2}{*}{0.002} \\
\hline Not Mandatory & 305 & 1.01 & 0.74 to 1.38 & \\
\hline \multicolumn{5}{|l|}{ Use of EGFR TK inhibitors } \\
\hline Mandatory & 84 & 1.43 & 0.65 to 3.16 & \multirow[t]{2}{*}{0.83} \\
\hline Not mandatory & 366 & 1.29 & 0.76 to 2.17 & \\
\hline
\end{tabular}

of participants not included in the analysis. A global quality score for each study was determined based on the reviewers' judgement of the importance of these aspects and consequent susceptibility of the results to bias [23].

The quality of a body of evidence for each individual outcome was summarized using the GRADE approach [24]. This approach involved considering the within study risk of bias (methodologic quality), directness of evidence, heterogeneity, precision of effect estimate and risk of publication bias.

\section{Outcomes measures}

The main outcomes of interests were:

1. Tumour overall response defined as complete or partial response as per RECIST criteria [25] or investigator defined criteria
2. Locoregional disease recurrence defined as recurrence of disease proven histologically or radiologically within the radiation fields or investigator defined criteria

3. Distant disease recurrence defined as recurrence of disease proven histologically or radiologically outside the radiation fields or investigator defined criteria

4. Recurrence free survival defined as time from diagnosis or start of any anti-cancer treatment till any disease recurrence proven histologically or radiologically or death from any cause

5. Overall survival defined as time from diagnosis or start of any anti-cancer treatment till death from any cause

6. Adverse events defined as per the Common Terminology Criteria for Adverse Events (CTCAE) version 3.0 or 4.0 [26] or as per investigator defined criteria

\section{EGFR mutant EGFR wild type Hazard Ratio Hazard Ratio}



Test for overall effect: $Z=1.44(P=0.15)$

Figure 5: Recurrence-free survival. 
Table 6: Subgroup effects on overall survival

\begin{tabular}{l}
\hline Subgroup \\
\begin{tabular}{|l|c|c|c|c|c|}
\hline Study Design & Patients & Hazard Ratio & $95 \%$ CI Interaction P \\
\hline Retrospective analysis of prospective single arm clinical trial & 84 & 1.00 & 0.52 to 1.94 & 0.96 \\
\hline Retrospective single institution cohort study & 453 & 0.98 & 0.73 to 1.32 \\
\hline Use of concurrent chemotherapy & 145 & 1.57 & 0.71 to 3.44 \\
\hline Mandatory & 392 & 0.93 & 0.69 to 1.24 \\
\hline Not Mandatory & & & & 0.22 \\
\hline Use of EGFR TK inhibitors & 84 & 1.00 & 0.52 to 1.94 \\
\hline Mandatory & 453 & 0.98 & 0.73 to 1.32 \\
\hline Not mandatory & & 0.96 \\
\hline
\end{tabular}
\end{tabular}

\section{Statistical analysis}

For dichotomous outcomes, i.e. tumour overall response, locoregional disease recurrence, distant disease recurrence and adverse events, we extracted the number of patients in each group who experienced the outcome of interest and the number of patients assessed to estimate a risk ratio (RR). The individual study's risk ratios were pooled using the Mantel-Haenszel method [27]. A RR of more than 1 for tumour overall response suggests an advantage for EGFR sensitizing mutations while risk ratio of more than 1 for the other dichotomous outcomes suggests an advantage for EGFR wild-type.

For time-to-event outcomes, i.e. recurrence free survival and overall survival, the log hazard ratios (HR) and their variances for time-to-event data were estimated using published methods when appropriate summary statistics or Kaplan-Meier curves were reported [28]. The individual study log HR and their variances were then combined using the generic inverse variance method [29]. A HR of less than 1 suggests an advantage for EGFR sensitizing mutations.

Statistical heterogeneity among the included studies' results was assessed by visual inspection of forest plots, chisquare tests and $\mathrm{I}^{2}$ statistic. A $P$ value higher than 0.1 for chisquare test and an $\mathrm{I}^{2}$ value of lower than $25 \%$ was interpreted as signifying a low level of heterogeneity [30]. All metaanalyses were performed with a random effects model.

\section{Subgroup analysis}

Subgroup analyses, determined a priori were performed to determine if the results were influenced

\begin{tabular}{|c|c|c|c|c|c|c|c|c|c|}
\hline \multirow[b]{2}{*}{ Study } & \multirow[b]{2}{*}{ [Hazard Ratio] } & \multicolumn{2}{|c|}{ EGFR mutant } & \multicolumn{2}{|c|}{ EGFR wild type } & \multirow{2}{*}{$\begin{array}{l}\text { Hazard Ratio } \\
\text { IV, Random, } 95 \% \mathrm{Cl}\end{array}$} & \multirow{2}{*}{\multicolumn{2}{|c|}{$\begin{array}{c}\text { Hazard Ratio } \\
\text { IV, Random, } 95 \% \mathrm{Cl}\end{array}$}} & \\
\hline & & D] SE & Total & Total & Weight & & & & \\
\hline Akamatsu 2014 & 0.11 & 0.41 & 13 & 31 & $11.4 \%$ & $1.12[0.50,2.49]$ & 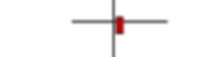 & & \\
\hline Hayashi 2012 & 0.25 & 0.56 & 11 & 23 & $6.1 \%$ & $1.28[0.43,3.85]$ & , & & \\
\hline Komaki 2015 & 0.22 & 0.73 & 4 & 37 & $3.6 \%$ & $1.25[0.30,5.21]$ & 1 & & \\
\hline Li 2011 & 0.02 & 0.28 & 39 & 48 & $24.3 \%$ & $1.02[0.59,1.77]$ & - & & \\
\hline Ready 2010 & -0.06 & 0.38 & 11 & 32 & $13.2 \%$ & $0.94[0.45,1.98]$ & - & & \\
\hline Tanaka 2015 & 0.55 & 0.48 & 29 & 75 & $8.3 \%$ & $1.73[0.68,4.44]$ & 1 & & \\
\hline Yagaishita 2015 & -0.28 & 0.24 & 29 & 155 & $33.1 \%$ & $0.76[0.47,1.21]$ & 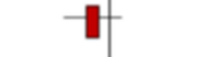 & & \\
\hline Total $(95 \% \mathrm{Cl})$ & & & 136 & 401 & $100.0 \%$ & $0.99[0.75,1.29]$ & 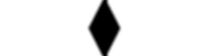 & & \\
\hline Heterogeneity: Ta & $\mathrm{l}^{2}=0.00 ; \mathrm{Chi}^{2}$ & $i^{2}=3.0$ & $=6(P=$ & $0.80) ; 1^{2}=0$ & & & & & \\
\hline Test for overall eff & ect: $Z=0.11$ & $(P=0$. & & & & $\begin{array}{lll}0.01 & 0.1\end{array}$ & 1 & 10 & 100 \\
\hline
\end{tabular}

Figure 6: Overall survival. 
by: the use of concurrent chemo-radiotherapy; the use of EGFR TK inhibitors and study design (prospective versus retrospective). Interaction test was used to compare differences between estimates from different subgroups [31].

\section{CONFLICTS OF INTEREST}

None.

\section{REFERENCES}

1. Fact Sheets by Cancer. Globocan.Iarc.Fr. (2017). http:// globocan.iarc.fr/Pages/fact_sheets_cancer.aspx (accessed 22 April 2017).

2. Travis W, Brambilla E, Burke A, Marx A, Nicholson A. Introduction to The 2015 World Health Organization Classification of Tumors of the Lung, Pleura, Thymus, and Heart. J Thorac Oncol. 2015; 10:1240-1242.

3. Rosell R, Moran T, Queralt C, Porta R, Cardenal F, Camps C, Majem M, Lopez-Vivanco G, Isla D, Provencio M, Insa A, Massuti B, Gonzalez-Larriba J, et al. Screening for Epidermal Growth Factor Receptor Mutations in Lung Cancer. N Engl J Med. 2009; 361:958-967.

4. Shi Y, Au J, Thongprasert S, Srinivasan S, Tsai C, Khoa M, Heeroma K, Itoh Y, Cornelio G, Yang P. A Prospective Molecular Epidemiology Study of EGFR Mutations in Asian Patients with Advanced Non-Small-Cell Lung Cancer of Adenocarcinoma Histology (PIONEER). J Thorac Oncol. 2014; 9:154-162.

5. Lee C, Brown C, Gralla R, Hirsh V, Thongprasert S, Tsai C, Tan E, Ho J, da Chu T, Zaatar A, Osorio Sanchez J, Vu $\mathrm{V}, \mathrm{Au} \mathrm{J}$, et al. Impact of EGFR Inhibitor in Non-Small Cell Lung Cancer on Progression-Free and Overall Survival: A Meta-Analysis. J Natl Cancer Inst. 2013; 105:595-605.

6. Lee C, Davies L, Wu Y, Mitsudomi T, Inoue A, Rosell R, Zhou C, Nakagawa K, Thongprasert S, Fukuoka M, Lord S, Marschner I, Tu Y, et al. Gefitinib or Erlotinib vs Chemotherapy for EGFR Mutation-Positive Lung Cancer: Individual Patient Data Meta-Analysis of Overall Survival. J Natl Cancer Inst. 2017; 109. https://doi.org/10.1093/jnci/ djw279.

7. Haaland B, Tan PS, de Castro G Jr, Lopes G. Meta-Analysis of First-Line Therapies in Advanced Non-Small-Cell Lung Cancer Harboring EGFR-Activating Mutations. J Thorac Oncol. 2014; 9:805-811

8. NCCN Clinical Practice Guidelines in Oncology. (2017). https://www.ncen.org/professionals/physician_gls/PDF/ nscl.pdf (accessed 22 April 2017).

9. Das A, Sato M, Story M, Peyton M, Graves R, Redpath S, Girard L, Gazdar A, Shay J, Minna J, Nirodi C. NonSmall Cell Lung Cancers with Kinase Domain Mutations in the Epidermal Growth Factor Receptor Are Sensitive to Ionizing Radiation. Cancer Res. 2006; 66:9601-9608.

10. Ready N, Jänne PA, Bogart J, Dipetrillo T, Garst J, Graziano S, Gu L, Wang X, Green MR, Vokes EE; Cancer, Leukemia
Group B. Chemoradiotherapy and gefitinib in stage III non-small cell lung cancer with epidermal growth factor receptor and KRAS mutation analysis: cancer and leukemia group B (CALEB) 30106, a CALGB-stratified phase II trial. J Thorac Oncol. 2010; 5:1382-1390.

11. Li F, Bai H, Li X, Wu M, Yu R, Shi A, Yin L, Wang J, Zhu G. Role of EGFR mutation status in patients with stage III non-squamous non-small cell lung cancer treated with chemoradiotherapy. Zhongguo Fei Ai Za Zhi. 2011; 14:715-718.

12. Hayashi H, Okamoto I, Kimura H, Sakai K, Nishimura Y, Nishio K, Nakagawa K. Clinical outcomes of thoracic radiotherapy for locally advanced NSCLC with EGFR mutations or EML4-ALK rearrangement. Anticancer Res. 2012; 32:4533-4537.

13. Akamatsu H, Kaira K, Murakami H, Serizawa M, Koh Y, Ono A, Shukuya T, Tsuya A, Nakamura Y, Kenmotsu H, Naito T, Takahashi T, Endo M, et al. The impact of clinical outcomes according to EGFR mutation status in patients with locally advanced lung adenocarcinoma who received concurrent chemoradiotherapy. Am J Clin Oncol. 2014; 37:144-147.

14. Komaki R, Allen P, Wei X, Blumenschein G, Tang X, Lee J, Welsh J, Witsuba I, Liu D, Hong W. Adding Erlotinib to Chemoradiation Improves Overall Survival but Not Progression-Free Survival in Stage III Non-Small Cell Lung Cancer. Intl J Radiat Oncol Biol Phys. 2015; 92:317-324.

15. Tanaka K, Hida T, Oya Y, Oguri T, Yoshida T, Shimizu J, Horio Y, Hata A, Kaji R, Fujita S, Sekido Y, Kodaira T, Kokubo M, et al. EGFR Mutation Impact on Definitive Concurrent Chemoradiation Therapy for Inoperable Stage III Adenocarcinoma. J Thorac Oncol. 2015; 10:1720-1725.

16. Yagishita S, Horinouchi H, Katsui Taniyama T, Nakamichi S, Kitazono S, Mizugaki H, Kanda S, Fujiwara Y, Nokihara H, Yamamoto N, Sumi M, Shiraishi K, Kohno T, et al. Epidermal Growth Factor Receptor Mutation Is Associated With Longer Local Control After Definitive Chemoradiotherapy in Patients With Stage III Nonsquamous Non-Small-Cell Lung Cancer. Int J Radiat Oncol Biol Phys. 2015; 91:140-148.

17. Ochiai S, Nomoto Y, Watanabe Y, Yamashita Y, Toyomasu Y, Kawamura T, Takada A, Noriko, Sakuma H. The impact of epidermal growth factor receptor mutations on patterns of disease recurrence after chemoradiotherapy for locally advanced non-small cell lung cancer: a literature review and pooled analysis. J Radiat Res. 2016; 57:449-459.

18. Zhang Z, Wang T, Zhang J, Cai X, Pan C, Long Y, Chen J, Zhou C, Yin X. Prognostic Value of Epidermal Growth Factor Receptor Mutations in Resected Non-Small Cell Lung Cancer: A Systematic Review with Meta-Analysis. Plos ONE. 2014; 9:e106053.

19. Shepherd FA, Lacas B, Le Teuff G, Hainaut P, Jänne PA, Pignon JP, Le Chevalier T, Seymour L, Douillard JY, Graziano S, Brambilla E, Pirker R, Filipits M, et al. Pooled Analysis of the Prognostic and Predictive Effects of TP53 Comutation Status Combined With KRAS or EGFR 
Mutation in Early-Stage Resected Non-Small-Cell Lung Cancer in Four Trials of Adjuvant Chemotherapy. J Clin Oncol. 2017; 35:2018-2027.

20. Lindeman NI, Cagle PT, Beasley MB, Chitale DA, Dacic S, Giaccone G, Jenkins RB, Kwiatkowski DJ, Saldivar JS, Squire J, Thunnissen E, Ladanyi M. Molecular Testing Guideline for Selection of Lung Cancer Patients for EGFR and ALK Tyrosine Kinase Inhibitors: Guideline from the College of American Pathologists, International Association for the Study of Lung Cancer, and Association for Molecular Pathology. J Mol Diagn. 2013; 137:828-860

21. Rekhtman N, Leighl N, Somerfield M. Molecular Testing for Selection of Patients With Lung Cancer for Epidermal Growth Factor Receptor and Anaplastic Lymphoma Kinase Tyrosine Kinase Inhibitors: American Society of Clinical Oncology Endorsement of the College of American Pathologists/International Association for the Study of Lung Cancer/Association for Molecular Pathology Guideline. Journal Of Oncol Pract. 2015; 11:135-136

22. RTOG $\mid$ Clinical Trials | Study Number 1306. Rtog.Org. (2017). https://www.rtog.org/ClinicalTrials/ProtocolTable/ StudyDetails.aspx?study=1306 (accessed 1 May 2017).

23. Methods for evaluating research guideline evidence. (2017). https://www.prosit.de/images/1/13/Merge.pdf (accessed 25 April 2017).
24. GRADE home. Gradeworkinggroup.Org. (2017). http:// www.gradeworkinggroup.org/ (accessed 25 April 2017).

25. RECIST 1.1 - PAREXEL. Irrecist.Com. (2017). http://www. irrecist.com/recist/ (accessed 25 April 2017).

26. Protocol Development | CTEP. Ctep.Cancer.Gov. (2017). https:/ctep.cancer.gov/protocoldevelopment/electronic_ applications/ctc.htm (accessed 25 April 2017).

27. Mantel N, Haenszel W. Statistical aspects of the analysis of data from retrospective studies of disease. J Natl Cancer Inst. 1959; 22:719-748.

28. Tierney J, Stewart L, Ghersi D, Burdett S, Sydes M. Practical methods for incorporating summary time-toevent data into meta-analysis. Trials. 8 (2007). https://doi. org/10.1186/1745-6215-8-16.

29. DerSimonian R, Laird N. Meta-analysis in clinical trials. Controlled Clin Trials. 1986; 7:177-188. https:/doi. org/10.1016/0197-2456(86)90046-2.

30. Higgins J. Measuring inconsistency in meta-analyses. BMJ. 2003; 327:557-560. https://doi.org/10.1136/bmj.327.7414.557.

31. Altman D. Statistics Notes: Interaction revisited: the difference between two estimates. BMJ. 2003; 326:219219. https://doi.org/10.1136/bmj.326.7382.219. 